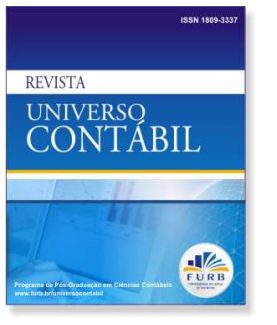

Revista Universo Contábil, ISSN 1809-3337

Blumenau, v. 9, n. 1, p. 135-146, jan./mar., 2013

doi:10.4270/ruc.2013108

Disponível em www.furb.br/universocontabil

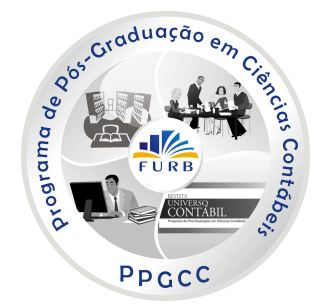

\title{
RELAÇÃO ENTRE A AUDITORIA INTERNA E A AUDITORIA EXTERNA E O IMPACTO NOS HONORÁRIOS DOS AUDITORES EXTERNOS1
}

\section{RELATION BETWEEN INTERNAL AND EXTERNAL AUDITING AND IS IMPACT ON THE EXTERNAL AUDITING FEES}

\section{LA RELACIÓN ENTRE LA AUDITORÍA INTERNA Y EXTERNA: IMPACTO SOBRE LOS HONORARIOS DE LOS AUDITORES EXTERNOS}

\author{
Ana Sofia Valente Cunha e Silva \\ Doutoranda em Contabilidade no Programa Doutoral de parceria entre a \\ Universidade de Aveiro e a Universidade do Minho \\ Endereço: Instituto Superior de Contabilidade e Administração \\ CEP: 3811-902 - Aveiro - Portugal \\ E-mail: asvsilva@hotmail.com \\ Telefone. 351917709194
}

Helena Coelho Inácio

Doutora em Contabilidade e Organização de Empresas pela Universidad Autónoma de Madrid Professora do Instituto Superior de Contabilidade e Administração da Universidade de Aveiro Endereço: Rua Associação Humanitária dos Bombeiros de Aveiro, Apartado 58 CEP: 3811-902 - Aveiro - Portugal

E-mail: helena.inacio@ua.pt Telefone. 351918465713

\section{RESUMO}

Ao longo dos últimos anos, dada a crescente exigência na fiabilidade da informação a fornecer aos mercados, tem vindo a crescer o papel da auditoria interna nas empresas. Acresce que teoricamente existem vários pontos de actuação que são comuns entre a auditoria interna e a auditoria externa. Assim, partindo do contributo da auditoria interna para a auditoria externa, faz-se uma revisão bibliográfica de um conjunto de estudos empíricos com vista à análise dos fatores que podem estar na origem da influência desse contributo na formação dos honorários dos auditores externos. Da análise efetuada concluiu-se que, por um lado, o

\footnotetext{
1 Artigo recebido em 14.02.2012. Revisado por pares em 26.06.2012. Reformulado em 05.08.2012. Recomendado para publicação em 07.08.2012 por Ilse Maria Beuren. Publicado em 31.03.2013. Organização responsável pelo periódico: FURB.
} 
contributo pode reduzir, ou não, os honorários; por outro, esse efeito está fortemente associado com a perspectiva com que a relação entre estes dois tipos de auditoria podem ser vistos, isto é, depende do facto dos dois tipos de auditoria serem vistos como complementos ou como substitutos. Esta conclusão deixa um campo de investigação em aberto em Portugal, onde os honorários foram liberalizados e a auditoria interna tem vindo a desenvolver-se significativamente.

Palavras-chave: Auditoria externa. Auditoria interna. Honorários.

\section{ABSTRACT}

Over the past few years given the growing demand on the reliability of the information provided to markets has increased the role of internal audit in companies. Moreover, theoretically there are several points of action that are common between internal audit and external audit. Thus, based on the contribution of internal audit to external audit we did a literature review of a set of empirical studies for the analysis of factors that may underlie the influence of this contribution in the formation of external auditor's fees. From the analysis performed it was concluded that on the one hand, the contribution may or may not reduce, the fees, on the other, this effect is strongly associated with the view that the relationship between these two types of audit can be seen, this is depends on whether the two types of audits are seen as complements or substitutes. This conclusion leaves an open field of research in Portugal, where the fees were liberalized and internal audit has been developing significantly.

Keywords: External audit. Internal audit. Fees.

\section{RESUMEN}

En los últimos años, dada la creciente demanda de la fiabilidad de la información proporcionada a los mercados, ha aumentado el papel de la auditoría interna en las empresas. Por otra parte, en teoría, hay varios puntos de acción que son comunes entre la auditoría interna y auditoría externa. Por lo tanto, sobre la base de la contribución de la auditoría interna y de la auditoría externa, se trata de una revisión de la literatura de un conjunto de estudios empíricos para el análisis de los factores que pueden ser causa de la influencia de esta contribución en la formación de los honorarios de los auditores externos. Del análisis realizado se concluyó que, por un lado, la contribución puede o no reducir las tasas, por el otro, este efecto se asocia fuertemente con la perspectiva como se observa la relación entre estos dos tipos de auditoría, esto es depende de si los dos tipos de auditorías son vistos como complementos o sustitutos. Esta conclusión deja un campo abierto de la investigación en Portugal, donde las tarifas se liberalizaron y la auditoría interna se tiene desarrollada significativamente.

Palabras clave: Auditoría externa. Auditoría interna. Honorarios.

\section{INTRODUÇÃO}

A auditoria interna e a auditoria externa têm um papel de importância crescente no mundo empresarial. São tipos de auditoria com campos de atuação próprios mas que apresentam pontos em comum, nomeadamente o contributo para a fiabilidade da informação. Numa primeira análise, dado este contributo, seria expectável que a existência de auditoria interna nas empresas conduzisse a uma redução nos honorários dos auditores externos, 
contudo nem sempre os resultados dos estudos corroboram esta ideia (Gerrard, Houghton e Woodliff, 1994; Stein, Simunic e O’Keefe, 1994; Sudwaidan e Qasin, 2010).

Em parte, este facto pode acontecer porque o cálculo dos honorários é influenciado por uma multiplicidade de fatores, nomeadamente a existência de Comissão de Auditoria (Abbot et. al., 2003; Stewart e Kent, 2006; Stewart e Munro, 2007), dimensão e complexidade da entidade auditada (Gerrard, Houghton e Woodliff, 1994; Sudwain e Qasin, 2010; Ho e Hutchinson, 2010), o risco (Basioudis 2002; Gist, 1992; Naser, Abdullhameed e Rana, 2007). No entanto, expurgando estes fatores espera-se que a auditoria interna continue a produzir efeitos nos honorários, tentando responder-se à questão: Quais os fatores que afetam o relacionamento dos dois tipos de auditoria que condicionam os honorários dos auditores externos?

Com vista a responder à nossa questão, interessa analisar quais os fatores subjacentes à utilização do trabalho do auditor interno pelo auditor externo e averiguar até que ponto o auditor externo utiliza o trabalho do auditor interno e o impacto que tal relacionamento exerce, consequentemente, nos honorários dos auditores externos.

\section{COORDENAÇÃO E COOPERAÇÃO ENTRE A AUDITORIA EXTERNA E INTERNA}

A auditoria interna pode tornar-se uma ferramenta muito útil para a auditoria externa uma vez que ao optar por utilizar o trabalho que o auditor interno desenvolve ao longo do ano, o auditor externo poderá efetuar um bom aproveitamento do conhecimento que aquele possui da empresa em questão, reduzir a realização de determinados procedimentos de auditoria, assim como, o tempo dispendido.

Wittington e Winters (1990) afirmaram que os auditores internos podem proporcionar prova de auditoria relativamente a várias contas do balanço ou classes de transações e à eficácia operacional das políticas e procedimentos de controlo da empresa.

Schneider (2009) afirmou que ao confiarem no trabalho da auditoria interna os auditores externos podem evitar a duplicação de determinados procedimentos de auditoria além de que os auditores internos apresentam um maior conhecimento do negócio, dos procedimentos e das políticas da empresa auditada. Contudo, de acordo com o autor os auditores externos devem manter a postura de independência que lhes é exigida.

Os auditores externos devem, de facto, preservar a sua independência e efetuar uma adequada avaliação do trabalho do auditor interno que lhes permita decidir sobre a utilização, ou não, do trabalho do auditor interno e, caso optem por essa utilização, definir ainda o nível de confiança a depositar nesse trabalho ou até que ponto podem utilizar esse trabalho. Neste sentido, a ISA $610, \S 11$, estabelece que para que possam utilizar o trabalho desenvolvido pelos auditores internos, os auditores externos, devem avalia-lo e realizar procedimentos com o objetivo de determinarem o seu nível de adequação. A ISA 610, §12 estabelece ainda que para avaliar o nível de adequação do trabalho do auditor interno, deve verificar a competência e formação técnica dos auditores internos, se o trabalho foi corretamente supervisionado, revisto e documentado, se foram obtidas provas adequadas que proporcionem conclusões razoáveis, se as conclusões estão adequadas e os relatórios elaborados estão consistentes com o trabalho formulado e se determinadas matérias não usuais são devidamente resolvidas.

Deste modo, e tal como mencionado por Wood (2004, p. 2), "auditores internos e externos têm forças diferentes que se combinam para aumentar a eficácia das auditorias". A combinação destes dois tipos de auditoria pode de facto permitir uma melhoria na eficácia da auditoria externa mas para que essa combinação resulte é necessário que o auditor externo tenha a perceção (após as devidas avaliações) de que o departamento de auditoria interna é credível, competente, objetivo, devidamente qualificado e que haja uma boa coordenação 
entre os auditores externos e os auditores internos o que nem sempre é possível. Wood (2004) também referiu que se não existir uma coordenação adequada entre os auditores externos e os auditores internos, pode existir duplicação do trabalho originando, assim, um aumento dos honorários dos auditores externos, sem que se verifique o correspondente aumento da eficácia da auditoria.

Golen (2008) pronunciou-se acerca dos principais obstáculos à comunicação entre os auditores internos e externos, nomeadamente: distorção ou omissão de informação solicitada, perceção por parte dos auditores externos da falta de credibilidade dos auditores internos, tendência por parte destes dois grupos de auditores para não se escutarem, resistência por parte dos auditores externos às opiniões de mudança/melhoria/inovação dadas pelos auditores internos, insuficiência por parte dos auditores internos de conhecimentos contabilísticos que exigem a cooperação entre ambos os auditores.

Al-Twaijry, Brierley e Gwilliam (2004), concluíram através de um estudo realizado na Arábia Saudita que não existe uma tendência por parte dos auditores externos de apoiar a auditoria interna e que o baixo nível de confiança depositado pelos auditores externos no trabalho dos auditores internos e o baixo nível de colaboração entre estes dois tipos de auditores está principalmente relacionado com a reduzida existência de auditores internos devidamente qualificados e com o reduzido tamanho dos departamentos de auditoria interna uma vez que estes limitam o âmbito e o alcance das funções exercidas. Assim, segundo os autores, as empresas devem empreender mais recursos no sentido de estabelecerem departamentos de auditoria competentes e independentes para que os auditores externos possam confiar no trabalho dos auditores internos. Esta última questão suscitada pelos referidos autores, é fundamental uma vez que o nível de credibilidade a atribuir à auditoria interna depende intimamente da postura da gestão. Mesmo que a gestão não envolva ou não tente envolver a auditoria interna nas suas questões é importante que demonstre preocupação em investir no departamento de auditoria interna e canalize uma parte dos recursos da empresa para tornar o departamento de auditoria devidamente qualificado.

Margheim (1986), verificou que os auditores externos reduzem as horas de auditoria planeadas se os auditores internos apresentarem um elevado nível de competência no desempenho do trabalho, contudo, essa redução só se verifica após a documentação, por parte dos auditores internos, de trabalho realizado numa área específica. Zain (2005), através da realização de um estudo na Malásia também verificou que a contribuição dada pela auditoria interna à auditoria externa é maior quando a dimensão da auditoria interna e a proporção de funcionários com experiência são elevadas.

A Figura 1 apresenta de uma forma esquemática a problemática associada com a coordenação ou cooperação entre a auditoria externa e interna.

Como podemos observar na Figura 1, a cooperação entre os dois tipos de auditoria pode melhorar a eficácia da auditoria externa, até porque a auditoria interna pode proporcionar prova para o trabalho de auditoria externa. Por outro lado, uma má coordenação entre elas pode levar a duplicação de trabalho. No entanto, a coordenação e cooperação entre os dois tipos de auditoria depende da confiança que o auditor externo pode depositar na auditoria interna que, por sua vez, está condicionada pela aplicação da ISA 610 e a manutenção da independência do auditor externo. Acresce que, para obtenção dessa confiança ou, mesmo, para o desenvolvimento de um ambiente favorável a uma adequada coordenação ou cooperação entre os dois tipos de auditoria, pode ser identificado um conjunto de impedimentos, nomeadamente, distorção ou omissão de informação solicitada, perceção de falta de credibilidade da auditoria interna, tendências para não se escutarem, resistência para a auditoria externa aceitar as opiniões da auditoria interna e insuficiência de qualificação dos auditores internos. 
Figura 1- Consequências e impedimentos na cooperação entre Auditoria Externa e Auditoria Interna

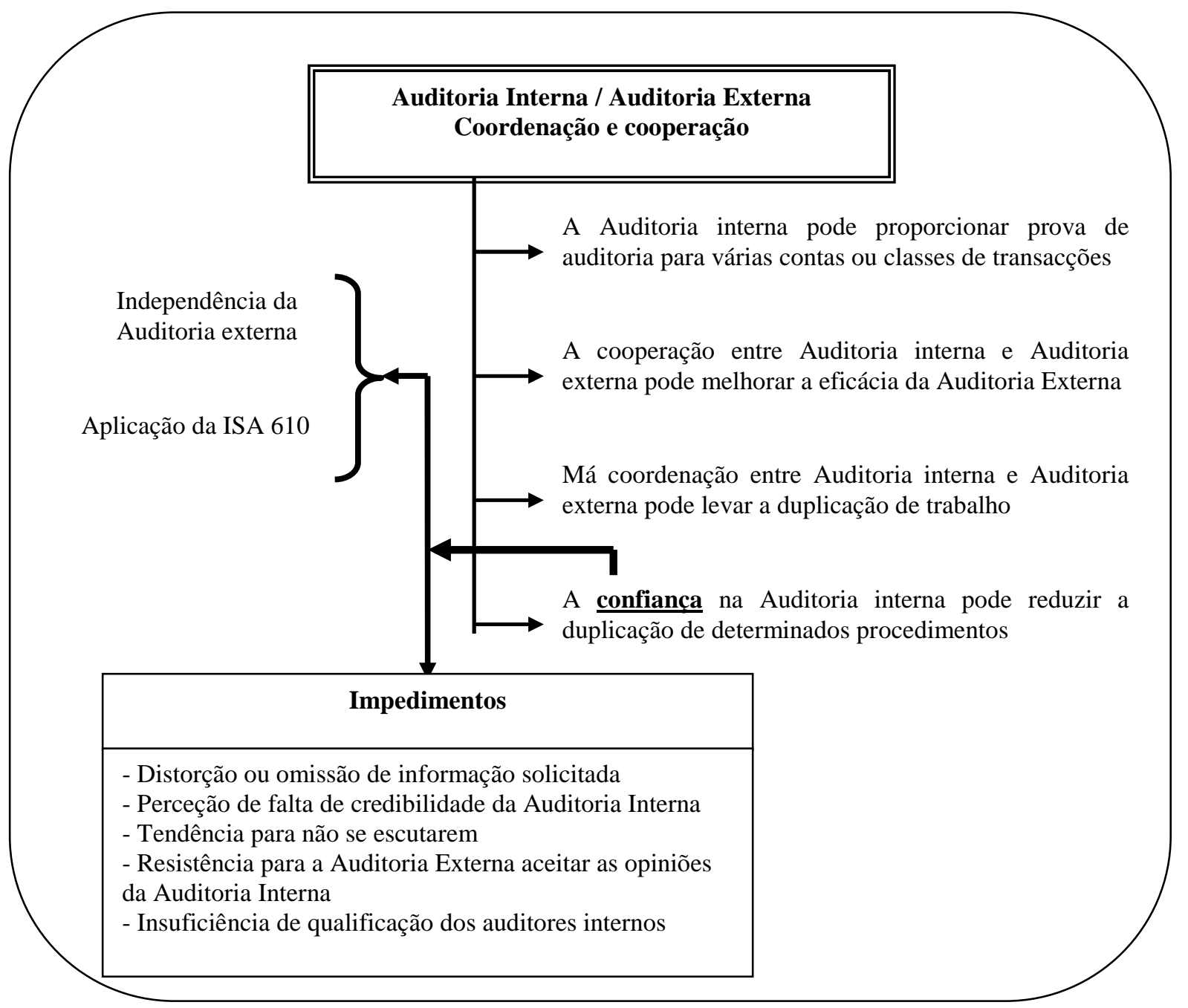

\section{RELAÇÃO ENTRE A AUDITORIA EXTERNA E INTERNA: COMPLEMENTO OU SUBSTITUIÇÃO?}

Definido o nível de confiança que os auditores externos depositam no trabalho efetuado pelos auditores internos importa aferir se este se reflete na redução do custo dos honorários dos auditores externos. Contudo, essa redução, ou não, não depende apenas desse nível de confiança mas também da forma como é encarado o relacionamento entre os dois tipos de auditoria, isto é, se a auditoria interna e a auditoria externa são vistas como substitutas ou como um complemento. Neste sentido, Singh e Newby (2010) defendem que a existência de um relacionamento positivo entre a auditoria interna e os honorários dos auditores externos indica que estes dois tipos de auditoria complementam-se, originando um maior controlo na empresa auditada, enquanto, a verificação de que tal relacionamento é negativo indica que a auditoria externa e a auditoria interna substituem-se.

$\mathrm{Na}$ verdade, os auditores externos podem depositar um elevado nível de confiança no trabalho prestado pelos auditores internos e tal não resultar numa redução dos custos da auditoria externa e sim num aumento. Assim, se a auditoria interna for considerada um complemento da auditoria externa, o que se pretende é um elevado nível de fiabilidade da informação e um maior controlo nessas empresas, sendo que temos uma maior incrementação da qualidade da auditoria interna mas, simultaneamente, um aumento nos honorários dos auditores externos. Pelo contrário, se a auditoria interna e a auditoria externa forem encaradas como substitutas uma da outra, então uma elevada contribuição proporcionada pela auditoria 
interna e um maior nível de confiança depositado neste tipo de auditoria permitirá que a auditoria externa incorra num menor esforço e empenho pelo que os honorários dos auditores externos serão, por consequência, menores.

De entre os estudos que encontraram uma relação de complemento temos o de Hay, Knechel e Ling (2008) que verificaram, através de um estudo na Nova Zelândia, que quanto maior for a dimensão da auditoria interna maior será a procura por serviços de auditoria externa existindo, portanto, uma relação de complemento. Por sua vez, Anderson e Zéghal (1994), confirmaram esta relação através de um estudo no Canadá, ao verificar a existência de um relacionamento significativo e positivo entre os custos da auditoria interna e os honorários dos auditores externos nas grandes empresas.

Stewart e Kent (2006), através da realização de um estudo na Austrália, verificaram que as empresas que incorrem num maior custo com os honorários dos auditores externos apresentam uma auditoria interna com uma maior qualidade. Este estudo inclui-se igualmente na perspectiva de complemento, isto é, existe um objetivo centrado na fiabilidade que leva a uma maior preocupação com a qualidade da auditoria interna e externa que se traduz também num aumento dos honorários do auditor externo. Singh e Newby (2010) também concluíram que as empresas que incorrem num maior custo com os honorários dos auditores externos apresentam funções de auditoria interna com uma maior dinâmica.

Diversos estudos constataram relacionamento entre a substituição de auditoria interna e externa. Wallace (1984, p. 20), em estudo realizado nos E.U.A, concluiu que "o investimento na função de auditoria interna produz cortes no custo dos serviços de auditoria externa". Ainda, que os auditores internos podem conduzir à redução dos honorários dos auditores externos através do aperfeiçoamento nos controlos da informação contabilística, de análises financeiras fiáveis, da prestação de apoio organizacional e de assistência na revisão de outros aspetos. Hong Kong, Ho e Hutchinson (2010) observaram que a contribuição dada pela auditoria interna pode substituir a realização de determinados testes substantivos pelos auditores externos e reduzir custos. Piazinni et al. (2010) verificaram que um aumento na qualidade da auditoria interna conduz a redução no risco de controlo e no esforço dos auditores externos. Prawitt, Sharp e Wood (2011) verificaram que a auditoria interna permite a redução dos honorários dos auditores externos por via da assistência direta prestada pelos auditores internos aos auditores externos e não pelo nível de confiança no trabalho dos auditores internos.

Ao analisar o relacionamento entre a contribuição dada pela auditoria interna à auditoria externa e os honorários dos auditores externos, Zain (2005) verificou que este é negativo e, mesmo não sendo significativo, tais resultados indicam que o tempo e o esforço economizado pelos auditores externos devido à contribuição dada pela auditoria interna, pode ser canalizado para áreas mais complexas que exijam um maior esforço da sua parte. Félix et al. (2005, p.75), ao analisarem o impacto que a confiança depositada no trabalho desenvolvido pelos auditores internos exerce na natureza, tempo e dimensão do esforço dos auditores externos, verificaram que "após controlar o risco de distorções avaliado, o grau de confiança influencia significativamente a oportunidade, mas não a natureza e extensão da prova".

Verifica-se por vezes que os auditores externos utilizam o trabalho do auditor interno como forma de economizar o tempo dispendido, mas nem sempre esse aproveitamento se reflete na quantidade/dimensão dos procedimentos de auditoria a aplicar sendo que tal está intimamente relacionado com a avaliação que o auditor externo efetua do risco de existência de distorções materiais, isto é, se o auditor considerar que este é elevado, então pode optar por não reduzir os procedimentos de auditoria ou reduzir até a um nível que lhe proporcione uma segurança razoável ou efetuar uma avaliação mais exaustiva ao trabalho do auditor interno.

Por outro lado, constatou-se que determinados estudos não encontraram um relacionamento significativo entre a auditoria interna e os honorários dos auditores externos, nomeadamente Gerrard, Houghton e Woodliff (1994), realizado na Austrália, Stein, Simunic e 
Keefe (1994), realizado nos E.U.A, Sudwaidan e Qasin (2010), efetuado na Jordânia.

Para Sudwaidan e Quasin (2010), a maioria dos auditores externos inquiridos, não consideraram a existência de uma associação entre o nível de confiança que depositam no trabalho desenvolvido pelos auditores internos e os seus honorários ou porque os auditores externos não consideram que os honorários recebidos são suficientes ou então, porque o nível de confiança depositado no trabalho dos auditores internos não apresenta uma significância que justifique uma redução nos seus honorários. Esta última perspetiva prende-se com o facto do auditor externo só poder, efetivamente, considerar o trabalho do auditor interno como base de prova se este cumprir o conjunto de requisitos estabelecidos na ISA 610. Não basta que exista auditoria interna na entidade auditada para que o auditor externo possa diminuir o seu trabalho, ou canalizar os seus esforços para áreas mais relevantes, sem afetar negativamente a eficácia ou eficiência da auditoria, é necessário avaliar e validar esse trabalho.

A Figura 2 apresenta os pressupostos das perspetivas referidas (complemento ou substituição). Na perspetiva de complemento o objetivo principal é o aumento de fiabilidade e na perspetiva de substituição é o aumento da eficiência não se perdendo eficácia. Quando os dois tipos de auditoria se complementam, o aumento da fiabilidade é atingido reforçando-se a auditoria externa, o que leva ao aumento dos honorários do auditor externo e aumento da eficácia de auditoria, resultado do facto da auditoria interna e externa trabalham para melhorar a fiabilidade da informação financeira. Na perspetiva da substituição, há um reforço no contributo da auditoria interna para a auditoria externa, com a consequente redução dos honorários deste e o aumento da sua eficiência, mas mantendo-se o mesmo nível de fiabilidade e eficácia. Pode-se obter aumento de eficácia se com a maior uso da auditoria interna se canalizar o tempo e esforço de auditoria externa para as áreas de maior relevância.

Figura 2 - Relação entre Auditoria Externa e Auditoria Interna como complemento ou substituição

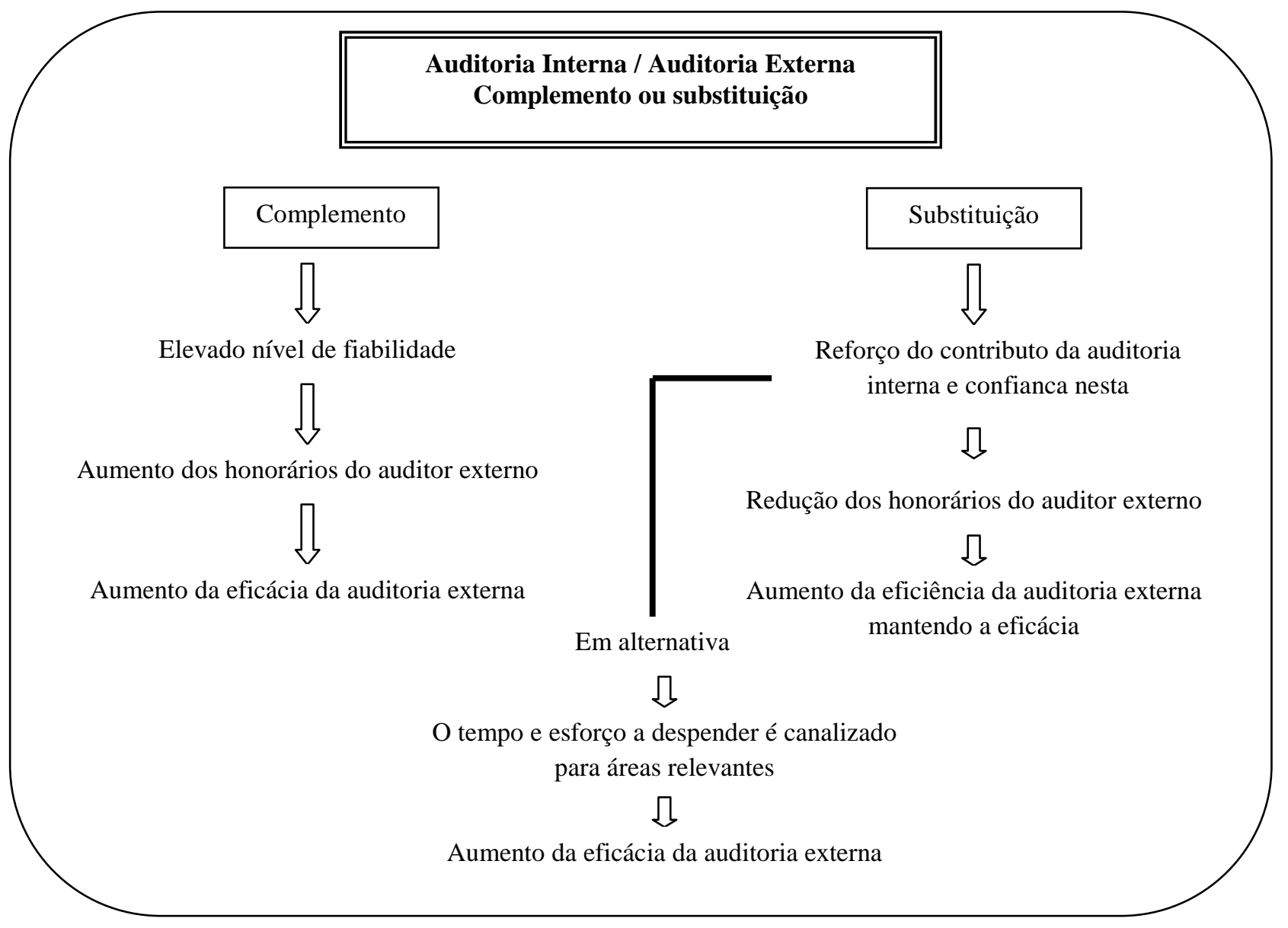




\section{A DECISÃO DE UTILIZAÇÃO DO TRABALHO DO AUDITOR INTERNO E O RISCO DE EXISTÊNCIA DE DISTORÇÕES MATERIAIS}

Ao decidir sobre a utilização do trabalho do auditor interno o auditor externo deve ter em consideração o risco de existência de distorções materiais tal como definido no §A6 da ISA 610: "A natureza, oportunidade e extensão dos procedimentos de auditoria realizados em trabalhos específicos dos auditores internos vai depender da avaliação do auditor externo relativamente ao risco de distorções materiais, à função de auditoria interna e ao trabalho específico do auditor interno". Ora, na avaliação do risco de existência de distorções materiais o auditor externo tem em consideração dois tipos de risco: o risco inerente (que inclui o risco de negócio e o risco inerente à própria natureza e complexidade das operações e das contas das Demonstrações Financeiras) e o risco de controlo.

Relativamente ao risco inerente, existem alguns estudos que analisaram a influência que este exerce no nível de confiança que o auditor externo deposita no auditor interno. Assim, alguns estudos constataram que o risco inerente influencia significativamente a decisão de confiança dos auditores externos nos auditores internos, pelo que quando este é elevado os auditores externos efetuam uma análise mais profunda ao trabalho do auditor interno.

Maletta (1993) constatou que o modo como a objetividade e o trabalho desenvolvido pelos auditores internos causa impacto na decisão de o auditor externo utilizar o trabalho dos auditores internos é influenciado pelo risco inerente, sendo que, aumenta a complexidade dos procedimentos de avaliação da objetividade e do trabalho desenvolvido pelo auditor interno quanto mais elevado for o risco inerente.

Whittington e Margheim (1993) observaram que o risco inerente não exerce influência significativa no nível de confiança a depositar nos auditores internos e, que por sua vez, a influência desta na realização de testes substantivos depende da natureza da asserção. Adicionalmente, observaram que os auditores externos realizam uma maior quantidade de testes de controlo ao trabalho dos auditores internos quando o nível de materialidade estabelecido é baixo. Assim, verificou-se que o nível de materialidade exerce um papel importante na avaliação que os auditores externos efetuam ao trabalho dos auditores internos. Ora, a avaliação do risco de auditoria por parte dos auditores externos e a influência que este exerce na avaliação aos auditores internos está implícita uma vez que o risco e a materialidade relacionam-se de forma inversa. Al-Arshani (2003) analisou o relacionamento entre o risco inerente e o nível de confiança depositado pelos auditores externos no trabalho dos auditores internos tendo verificado que este não é significativo. Em contrapartida, o autor concluiu que ao planear a auditoria, o auditor externo tem em consideração o risco de existência de litígios, constatando assim que a rendibilidade da empresa auditada afeta significativamente e positivamente o grau de confiança que o auditor externo deposita na auditoria interna. Neste contexto, o risco inerente visto como um todo, não é considerado como um fator relevante no processo de decisão do auditor externo quanto à utilização do trabalho do auditor interno, contudo é atribuída relevância ao risco de negócio.

Arel (2006) verificou que os auditores externos consideram os auditores internos em outsourcing mais objetivos e mais independentes do que os que são funcionários da empresa. Verificou ainda que o nível de risco do negócio não exerce influência significativa sobre o nível de confiança do auditor externo no auditor interno. Contudo, a autora verificou que o risco de negócio afeta a relação entre o tipo de auditoria interna, o risco de existência de distorções materiais numa determinada conta e o nível de confiança a atribuir pelos auditores externos aos auditores internos. Assim, quando o nível de risco é elevado este relacionamento é significativo e o processo de decisão do nível de confiança a depositar no auditor interno é complexo.

Relativamente ao risco de controlo, a existência de uma auditoria interna com 
qualidade permite reduzir o risco de controlo além de que o auditor externo ao avaliar o trabalho do auditor interno e tendo resultados favoráveis poderá executar um menor número de testes de controlo. Contudo, quando se está perante PME's o auditor externo assume que o risco de controlo é elevado e tem tendência a substituir os testes de controlo por testes de dupla finalidade.

\section{O PAPEL DA GESTÃo NO RELACIONAMENTO ENTRE A AUDITORIA EXTERNA E INTERNA}

Outra questão importante a considerar, é o papel desempenhado pela gestão neste relacionamento uma vez que os honorários a pagar aos auditores externos também poderão depender do modo como a gestão encara este relacionamento. Assim, a gestão poderá investir na qualidade da auditoria interna e influenciar/incentivar, direta ou indiretamente, o auditor externo a confiar no trabalho desenvolvido pelos auditores internos como forma de reduzir os custos da auditoria externa, desempenhando a auditoria interna a função de substituta da auditoria externa.

Ao pronunciar-se sobre este assunto, Schneider (2009) referiu que os investimentos no departamento de auditoria interna são efetuados com o intuito de permitir que o custo total de auditoria (auditoria interna mais externa), seja menor do que se a atividade de auditoria interna não existisse na empresa.

Félix, Gramling e Maletta (2001) também constataram, que quanto maior for a contribuição dada pela auditoria interna à auditoria externa, menor será o custo incorrido com os honorários dos auditores externos. Os autores mencionaram também que o cliente pode influenciar essa contribuição ao proporcionar um aumento da qualidade da auditoria interna, da disponibilidade da gestão e ao facilitar a comunicação/coordenação, entre os auditores externos e os internos.

Haron et al. (2004) também verificaram, com um estudo elaborado na Malásia, que a auditoria externa será mais rentável se a gestão da empresa proporcionar o desenvolvimento de critérios concretos relativos à competência e desempenho dos auditores internos.

Ao avaliarem a auditoria interna, os auditores externos têm também em consideração a credibilidade da gestão, as políticas e a organização da empresa e se a separação entre a gestão e a auditoria interna está bem definida. Deste modo, Messier et al. (2010) constataram que quando os auditores externos têm a perceção de que a auditoria interna é utilizada como uma forma de posicionar os auditores internos em postos de trabalho que são próprios da gestão, cobram honorários mais elevados uma vez que, mesmo não apresentando uma competência inferior, apresentam uma menor objetividade.

Desai, Roberts e Srivastana (2010) desenvolveram um modelo analítico com o objetivo de analisarem a força/qualidade da auditoria interna, tendo verificado que os auditores externos não podem considerar que a atividade da auditoria interna é forte, se não possuírem conhecimento ou possuírem um conhecimento negativo quanto à qualidade da governação corporativa, mesmo quando a perceção que possuem em relação à competência, objetividade e ao desempenho dos auditores internos é positiva.

\section{CONCLUSÕES}

A análise efetuada permitiu concluir que, de uma forma geral, uma boa cooperação entre os auditores externos e internos, a perceção de que existe uma adequada separação entre os interesses da gestão e o papel da auditoria interna na organização, a existência de auditores internos credíveis, competentes, objetivos, a existência de um baixo nível do risco de distorções materiais, podem permitir aos auditores externos incorrer num menor esforço. Contudo, tal redução no esforço dos auditores externos nem sempre resulta em redução dos 
seus honorários, depende do modo como é encarado o relacionamento entre a auditoria externa e a auditoria interna, isto é, se são consideradas como um complemento ou como substitutas. Sendo encaradas como substitutas, uma maior confiança no trabalho do auditor interno poderá originar uma diminuição do esforço dos auditores externos e, consequentemente, do custo dos seus honorários.

Em contrapartida, ao serem vistas como um complemento pretende-se aumentar a verificação da informação processada pela organização e, consequentemente, a qualidade da auditoria o que pode originar, pelo contrário, um aumento nos seus honorários. Desta forma, podemos afirmar que existem diferentes fatores que influenciam o relacionamento entre auditoria interna e externa e que de forma indireta culminam num efeito nos honorários do auditor externo. Contudo, as nossas conclusões estão limitadas à revisão bibliográfica efetuada. Será interessante no futuro, atendendo à liberalização dos honorários dos auditores e à crescente importância da auditoria interna em Portugal, estudar estes diferentes fatores e relacionamentos na nossa realidade.

\section{REFERÊNCIAS}

ABBOT, L.J.; PARKER, S.; PETERS, G.F.; RAGHUNANDAN K. The Association between Audit Committee Characteristics and Audit Fees. Auditing: A Journal of Practice and Theory, v. 22, n. 2, p. 17-32, 2003. http://dx.doi.org/10.2308/aud.2003.22.2.17

AL - ARSHANI, M. The Effect of Inherent Risk, Knowledge Spillover, and Litigation Risk on External Auditors' Reliance on Client's Internal Audit Functions. University of Arkansas. Tese de doutoramento, 2003. Disponível na: PROQUEST. Consultado em 03 janeiro de 2011.

AL - TWAIJRY, A.A.M.; BRIERLEY, J. A.; GWILLIAM, D.R. An Examination of the Relationship Between Internal and External Audit in the Saudi Arabian Corporate Sector. Managerial Auditing Journal, v. 19, n. 7, p. 929-944, 2004. http://dx.doi.org/10.1108/02686900410549448

ANDERSON, T.; ZÉGHAL, D. The Pricing of Audit Services: Further Evidence from the Canadian Market. Accounting and Business Research, v. 24, n. 95, p. 195-207, 1994. http://dx.doi.org/10.1080/00014788.1994.9729479

AREL, B. Two Studies on the Effect of Internal Audit Source on Reliance Decisions. Arizona State University. Tese de doutoramento. Disponível na: PROQUEST. Consultado em 03 janeiro de 2011.

BASIOUDIS, I.G. The UK Market for Audit Services Deregulation and Auditing Pricing in the Small Client Segment. International Journal of Economics and Business, v. 2, n. 1, p.188-210, 2002.

DESAI, V.; ROBERTS, R. W.; SRIVASTANA, R.P. An Analytical Model for External Auditor Evaluation of the Internal Audit Function Using Belief Functions. Contemporary Accounting Review. v. 27, n. 2, p. 346, 2010. http://dx.doi.org/10.1111/j.19113846.2010.01023_4.x

FELIX, W.L.; GRAMLING, A.A.; MALETTA, M.J. The Contribution of Internal Audit as a Determinant of External Audit Fees and Factors Influencing This Contribution. Journal of Accounting Research, v. 39, n. 3, p.513-534, 2001. http://dx.doi.org/10.1111/1475679X.00026

FELIX, W.L.; KIZIRIAN, T.; SNEATHEN, L. DWIGHT Jr. The Effect of an Internal Audit Function on Audit Effort. Academy of Accounting and Financial Studies Journal, v. 9, n. 
1, p.75-92, 2005.

GERRARD, I.; HOUGHTON, K.; WOODLIFF, D. Audit Fees: The Effects of Auditee, Auditor and Industry Differences. Managerial Auditing journal, v. 9, n. 7, p. 3-11, 1994. http://dx.doi.org/10.1108/02686909410067534

GIST, W.E. Explaining Variability in External Audit Fees. Accounting and Business Research, v. 23, n. 89, p.79-84, 1992. http://dx.doi.org/10.1080/00014788.1992.9729863

GOLEN, S. Communication Barriers Between Internal and External Auditors. ABEA Journal, v. 27 (outono), p. 35-43, 2008.

HARON, H; CHAMBERS, A.; RAMSI, R.; ISHAK, I. The Reliance of External Auditors on Internal Auditors. Managerial Auditing Journal, v. 19, n. 9, p.1148-1159, 2004. http://dx.doi.org/10.1108/02686900410562795

HAY, D.; KNECHEL, W.; LING, J. Evidence on the Impact of Internal Control and Corporate Governance on Audit Fees. International Journal of Auditing, v. 12, n. 1, p. 924, 2008. http://dx.doi.org/10.1111/j.1099-1123.2008.00367.x

HO, S.; HUTCHINSON, M. Internal Audit Department Characteristics/Activities and audit fees: Some Evidence from Hong Kong Firms. Journal of International Accounting, $\begin{array}{lllllll}\text { Auditing and Taxation, } & \text { v. 19, n. } 2010 .\end{array}$ http://dx.doi.org/10.1016/j.intaccaudtax.2010.07.004

ISA 610. Using the Work of External Auditors. International Federation of Accountants. Handbook of International Quality Control, Auditing, Review, Other Assurances, and Related Services Pronouncements, 2010 Edition - Part I.

MALETTA, M. An Examination of Auditors' Decision to Use Internal Auditors as Assistants: The effect of Inherent Risk. Contemporary Accounting Research, v. 9, n. 2, p. 508-525, 1993. http://dx.doi.org/10.1111/j.1911-3846.1993.tb00895.x

MARGHEIM, L. Further Evidence on External Auditors' Reliance on Internal Audit. Journal of Accounting Research, v. 24, n. 1, p. 194-205, 1986. http://dx.doi.org/10.2307/2490813

MESSIER JR, W. F.; REYNOLDS, J. K.; SIMON, C. A.; WOOD, D. A. The Effect of Using the Internal Audit Function as a Management Training Ground on the External Auditor's Reliance Decision. Accounting Review. 2010. Disponível na: Social Science Research Network. Consultado em 10 maio de 2011.

NASER, K.; ABDULLHAMEED, H.; RANA, N. Determinants of Audit Fees: Empirical Evidence from Emerging Economy. International Journal of Commerce and Management, v. 17, n. 3, p. 239-254, 2007. http://dx.doi.org/10.1108/10569210710833635

PISSINI, M.; LIN, S.; VARGUS, M. E.; ZIEGENFUSS, D. E. The Impact of Internal Audit Function Quality and Contribution on Audit Delays. 2010. Disponível na: Social Science Research Network. Consultado em 03 janeiro de 2011. http://dx.doi.org/10.2139/ssrn.1673490

PRAWITT, D.F; SHARP, N. Y.; WOOD, D.A. Reconciling Archival and Experimental Research: Does Internal Audit Contribution Affect the External Audit Fee? Behavioral Research in Accounting. v. 23, n. 2, p. 187-206, 2011. http://dx.doi.org/10.2308/bria-10065

SCHNEIDER, A. The Nature, Impact and Facilitation of External Auditor Reliance on Internal Auditing. Academy of Accounting and Financial Studies Journal, v. 13, n. 4, p.4153, 2009.

SINGH, H.; NEWBY, R. Internal Audit and Audit fees: Further Evidence. Managerial 
$\begin{array}{lllllllll}\text { Auditing Journal, } & \text { v. } & 25, & \text { n. } & 4, & \text { p. } & 309-327, & 2010 .\end{array}$ http://dx.doi.org/10.1108/02686901011034153

STEIN, M.T.; SIMUNIC, D.A.; O' KEEFE, T.B. Industry Differences in the Production of Audit Services. Auditing: A Journal of Practice and Theory, v.13, n. 1, p. 128-142, 1994.

STEWART, J.; KENT, P. Relation Between External Audit Fees, Audit Committee Characteristics and Internal audit. Accounting and Finance, v. 46, n. 3, p. 387-404, 2006. http://dx.doi.org/10.1111/j.1467-629X.2006.00174.X

STEWART, J.; MUNRO, L. The Impact of Audit Committee Existence and Audit Committee Meeting Frequency on the External Audit: Perceptions of Australian auditors. International Journal of Auditing, v. 11, n. 1, p. 51-69, 2007. http://dx.doi.org/10.1111/j.10991123.2007.00356.x

SUWAIDAN, M.S.; QASIM, A. External Auditors' Reliance on internal auditors and its impact on audit fees an empirical investigation. Managerial Auditing Journal, v. 25, n. 6, p. 509-525, 2010. http://dx.doi.org/10.1108/02686901011054845

WALLACE, W.A. Internal Auditors Can Cut Outside CPA costs. Harvard Business Review, v. 62, n. 2, p. 16-20, 1984.

WHITTINGTON, R.; L. MARGHEIM The Effects of Risk, Materiality, and Assertion Subjectivity on External Auditors' Reliance on Internal Auditors. Auditing: A Journal of Practice and Theory, v. 12, n. 1, p. 50-64, 1993.

WHITTINGTON, A.; WINTERS, J. Considering the Work of an Internal Auditor, The CPA Journal, v. 60, n. 4, p.28-34, 1990.

WOOD, David A. Increasing Value Through Internal and External Auditor Coordination. The Institute of Internal Auditors Research Foundation, 2004.

ZAIN, M. M. The Impact of Audit Committee and Internal Audit Attributes on Internal Audit Contribution to Financial Statement Audits and Audit Fees: Perceptions of Malaysian Internal Auditors. 2005. Disponível em: <http://www4.gu.edu.au:8080/adtroot/public/adt-QGU20060814.111202/index.html>. 